\title{
Editorial on: are we achieving ultimative limits of the minimally invasive thoracic surgery?
}

\author{
Paolo N. C. Girotti^ \\ Department of General, Visceral and Thoracic Surgery, Landeskrankenhaus Feldkirch, Feldkirch, Austria \\ Correspondence to: Paolo N. C. Girotti, MD. Department of General, Visceral and Thoracic Surgery, Landeskrankenhaus Feldkirch, Carinagasse 47, \\ 6800 Feldkirch, Austria. Email: paolo.girotti@vlkh.net. \\ Comment on: Chen J, Ang KL, Wang C, et al. Minimally invasive carinal reconstruction using bronchial flap and omental flap reinforcement. Ann \\ Thorac Surg 2021. [Epub ahead of print]. doi: 10.1016/j.athoracsur.2021.06.014.
}

Submitted Sep 11, 2021. Accepted for publication Oct 08, 2021.

doi: 10.21037/tlcr-21-748

View this article at: https://dx.doi.org/10.21037/tlcr-21-748

\section{Introduction}

"We have demonstrated that this combination of minimally invasive approaches can be safely performed with a good post-operative outcome in a patient treated with neoadjuvant therapy" (1). The last sentence of Chen $e t$ al. clearly explains that new ideas in surgery allow to improve step-by-step the quality of the standard treatment and to open new doors in terms of technical choices, particularly in complex cases. Nowadays, video assisted thoracoscopic (VATS) approach is widely considered by the entire scientific community and the surgical society as the gold standard approach in the case of early and advanced lung cancer (2-4).

However, I would like to propose and shortly discuss three main questions that arise spontaneously reading the above mentioned article by Chen and that are still debated in the surgery community:

(I) Where do we draw the limits of the VATS carinal/ tracheal procedures?

(II) Should the advance surgery be centralized in high volume centres or could each skilled surgeon individually approach challenging carinal and tracheal diseases (tumors or benignant stenosis) regardless of the total number of patients treated on a year basis?

(III) What is the future development of carina/tracheal resections technique (robotic technique-robotic assisted thoracoscopy (RATS)—and spontaneous ventilation thoracoscopy-SS-VATS)?

\section{Discussion}

\section{Where do we draw the limits of the VATS carinal/tracheal procedures?}

One of the early reports of carinal resection was in 1950 by Abbott where 4 patients underwent right pneumonectomy with en bloc excision of the carina (5). Barclay and colleagues reported the first European experience of carinal resection with reconstruction in 1957 (6). In 1982 the first standardized carinal resection and reconstruction, associated with pneumonectomy, were published by Deslauriers et al. (7). However also during the 80s this type of procedure was considered a high-risk operation as regards morbidity/mortality (mortality rates were up to $30 \%$ ). Therefore, tracheal or bronchial resections were performed only in high volume centres and by highly skilled surgeons (8-10). Few years later bronchial or tracheal resections without associated pneumonectomy, in the case of central airway lesions, continue to carry the same technical complexity as to airway reconstruction and management. Although the early development of tracheal surgery can be attributed to a limited number of surgeons (10-12),

$\wedge$ ORCID: 0000-0002-0554-5865. 
the technical aspects of modern tracheal surgery were pioneered by Grillo $(8,9)$, who authored what is considered the definitive text on the subject entitled, "Surgery of the Trachea and Bronchi" published in 2004. However, also great pioneers of the airways surgery reported a high rate of postoperative complications after bronchial resection and reconstruction $(6,7,10,13)$. Grillo published his experience on 36 patients who underwent carinal resection with primary reconstruction from 1962 to 1981 with an operative mortality of 13\% (8). In 1999, Mitchell et al. reported a severe postoperative mortality on 143 primary carinal resections since 1962 (12.7\%) (14).

Obviously, not only in our opinion, not new specific technical aspects for carinal/tracheal resection/ reconstruction, introduced in the last 40 years, but the progress in anesthesia, perioperative care and careful patient selection could be considered as the cornerstones for improved patient outcomes. In fact, during the 90s, after the worldwide introduction of the standardized perioperative anesthetic care a large number of authors have demonstrated the feasibility of such complex procedures which reduced the operative and postoperative morbidity/ mortality substantially (10,15-17). From 2000 onwards a considerable amount of series have been reported in literature and more authors have been encouraged to show their results and any new technical improvements. In 2013, Eichhorn et al. (18) published a series of 64 patients who underwent carinal resection with an operative mortality of $3.1 \%$. Until 2010 the carinal or tracheal resection was considered a "highly complex procedure" and no author had the courage to criticize the need of choice of an "open approach" for this type of operation. Since 2009 many Asian groups started to evaluate the feasibility of procedures involving the lower trachea tract which followed also the VATS approach. They reported many large series which confirmed that minimally invasive approaches may offer even a further reduction in morbidity and mortality (19-22). Shao et al. published a series of 139 patients who underwent minimally invasive bronchial and vascular sleeve resection for malignant tumors and who reported a major postoperative morbidity less than $1 \%$ (23). In $2016 \mathrm{Li}$ et al. showed no perioperative or postoperative major morbidity after VATS-carina resection for malignant or benign disease (19). These findings were compared without important bias with the previously reported postoperative mortality and morbidity rates after open thoracotomy $(24,25)$. Although VATS tracheal surgery was a feasible procedure in their article (19), there were two main limitations of VATS tracheal/carinal procedures: VATS procedures are typically more challenging because of the steep learning curve and inadequacy of palpation and direct vision, as compared to "open surgery" (26).

Petersen and Ujiie also suggest that there are other additional important limitations in the case of VATS carinal resection: the difficulty to manage an optimal intraoperative $2 \mathrm{D}$ view (the adjustment of the monitor view during the operation), the high risk to achieve an insufficient oncological resection and the complexity to plan a good arrangement with the anesthesiologist during airway resection (proper airway management during the reconstruction) $(26,27)$.

This short overview over the past 30 years of the literature in the case of carinal/tracheal procedure (from "high risk open" to "safety minimally invasive" procedure) showed that surgeons are interested in developing new surgical techniques and in offering an ever higher surgical standard to their own patients. It is therefore easy to answer the first question: there are no predetermined limits for the surgery and the technical procedures will be more and more complex, subject to reasonable and acceptable concepts of surgical safety.

\section{Should the advance surgery be centralized in high volume centers or could each skilled surgeon approach challenging carinal and tracheal diseases (tumors or benignant stenosis) regardless of the centers cases?}

Alam et al. has clearly summarized in his article that all advanced lobectomy should be carried out mainly through minimally invasive means (4). However, it is crucial that thoracic surgeons keep in mind that extended resections by VATS are the result of a long experience (both in VATS and in open extended resections). This level of experience and skill is an indispensable precondition to propose a thoracoscopic approach for a planned complex major resection $(27,28)$. Specific data about the learning curve in case of carinal/tracheal resection are not available but we can assume that airways resection and reconstruction could be considered as a "very" complex procedure that few surgeons could manage and manage safely with acceptable intraoperative morbidity. Therefore, only a high volume center permit young surgeon to achieve following skills:

* To quickly collect a sufficient number of standard lobectomy to achieve a subsequent step of difficulty with a high level of intraoperative safety and standardization. 
* To create a good arrangement with the anesthesiologist, particularly during the tracheal section, as previously mentioned.

* To gain an adequate experience as to the selection of the type of patients suitable for this type of procedure.

It is also important to consider that during the ESTS 2014, the consensus proposed a minimum of 50 resections as the minimum number of procedures sufficient to achieve technical proficiency in VATS lobectomy and at least 20 cases per year in order to maintain operative skills (2). Therefore, if we assume that the same criteria apply also to carina/trachea operations, (50 total resections and 20 cases/year) it is quite impossible that a single surgeon could satisfy them even at high volume centres. However, there is a consensus that only minimally invasive expert surgeons could conduce a carinal/tracheal safely. Definitely, VATS carinal/tracheal procedure can in theory be taught to any thoracic surgeon who has VATS expertise but ideally the learning path should be standardized and earlier problems should be taken into consideration when planning a VATS carinal/tracheal resection training program in a hospital with no sufficient experience in airways resection.

\section{Which is the future development of carinal/tracheal technique?}

In the last 10 years we have witnessed an expansion of the spread of the robot, nevertheless, it's still not clear the role of the RATS also in the case of advanced lung cancer. Many groups, from high volume center, showed optimal results, sometimes better than VATS, in term of conversion rate, oncological outcome and operative/postoperative morbidity $(29,30)$. Therefore, Abbas suggests the robotic approach should carry in the near future the same indications as for open thoracotomy (30) also because this surgical system has become a platform for ongoing technological development and new technological innovation will allow all surgeon to perform challenging procedures, such as carinal/tracheal resections. Prototypes for haptic feedback will provides surgeons with tactile sensations similar to that experienced during open surgery. Systems for image overlaying, would allow the operating team to superimpose a reconstructed 3-dimensional study (such as a CT scan or MRI) over the real-time surgical image in order to be able to identify important anatomical structures and target pathology below the pleural surface.

However, some authors report first robot experiences with RATS carina resection $(31,32)$ and they conclude that robot platform "might be a good choice to complete some complex thoracic procedure in a minimally invasive manner". The scientific community agrees that robotic procedures must be conducted in highly specialized centers but it's also clear that the developing will allow an increasing number of surgeons to perform the advance thoracic surgery. Currently the lack of tactile feedback, the distant from the patient and the high costs of the procedure might to limit the surgical indications, but for sure in few years these problems will be solved and the robot system could overtake in terms of efficiency and speed the open surgery.

\section{Conclusions}

Congratulations to the authors on an excellent presentation and study results. Authors have provided a clear explanation about the new surgical strategy used in this challenging cases. Not only the technique and the intraoperative airways control are the most challenging aspect in this procedure, but in our opinion the highlight of this study is the appropriately multidisciplinary selection of the patients to arrange optimal postoperative result in term of morbidity/mortality.

\section{Acknowledgments}

Funding: None.

\section{Footnote}

Provenance and Peer Review: This article was commissioned by the editorial office, Translational Lung Cancer Research. The article did not undergo external peer review.

Conflicts of Interest: The author has completed the ICMJE uniform disclosure form (available at https://dx.doi. org/10.21037/tlcr-21-748). The author has no conflicts of interest to declare.

Ethical Statement: The author is accountable for all aspects of the work in ensuring that questions related to the accuracy or integrity of any part of the work are appropriately investigated and resolved.

Open Access Statement: This is an Open Access article distributed in accordance with the Creative Commons Attribution-NonCommercial-NoDerivs 4.0 International License (CC BY-NC-ND 4.0), which permits the non- 
commercial replication and distribution of the article with the strict proviso that no changes or edits are made and the original work is properly cited (including links to both the formal publication through the relevant DOI and the license). See: https://creativecommons.org/licenses/by-nc-nd/4.0/.

\section{References}

1. Chen J, Ang KL, Wang C, et al. Minimally invasive carinal reconstruction using bronchial flap and omental flap reinforcement. Ann Thorac Surg 2021. [Epub ahead of print]. doi: 10.1016/j.athoracsur.2021.06.014.

2. Yan TD, Cao C, D'Amico TA, et al. Video-assisted thoracoscopic surgery lobectomy at 20 years: a consensus statement. Eur J Cardiothorac Surg 2014;45:633-9.

3. Bendixen M, Jørgensen OD, Kronborg C, et al. Postoperative pain and quality of life after lobectomy via video-assisted thoracoscopic surgery or anterolateral thoracotomy for early stage lung cancer: a randomised controlled trial. Lancet Oncol 2016;17:836-44.

4. Alam NZ, Flores RM. Extended video-assisted thoracic surgery (VATS) lobectomy. Minerva Chir 2016;71:67-71.

5. Abbott OA. Experiences with the surgical resection of the human carina, tracheal wall, and contralateral bronchial wall in cases of right total pneumonectomy. J Thorac Surg 1950;19:906-22.

6. Barclay RS, McSwan N, Welsh TM. Tracheal reconstruction without the use of grafts. Thorax 1957;12:177-80.

7. de Perrot M. 50th Anniversary Landmark Commentary on Deslauriers J, Beaulieu M, Benazera A, McClish A. Sleeve pneumonectomy for bronchogenic carcinoma. Ann Thorac Surg 1979;28:465-74. Ann Thorac Surg 2015;100:387.

8. Grillo HC. Carinal reconstruction. Ann Thorac Surg 1982;34:356-73.

9. Grillo HC. Surgery of the Trachea and Bronchi. Hamilton: BC Decker, 2004.

10. Dartevelle PG, Macchiarini P, Chapelier AR. 1986: Tracheal sleeve pneumonectomy for bronchogenic carcinoma: report of 55 cases. Updated in 1995. Ann Thorac Surg 1995;60:1854-5.

11. D'Amico TA. Thoracoscopic lobectomy: evolving and improving. J Thorac Cardiovasc Surg 2006;132:464-5.

12. Demmy TL, James TA, Swanson SJ, et al. Troubleshooting video-assisted thoracic surgery lobectomy. Ann Thorac Surg 2005;79:1744-52; discussion 1753.

13. Jensik RJ, Faber LP, Kittle CF, et al. Survival in patients undergoing tracheal sleeve pneumonectomy for bronchogenic carcinoma. J Thorac Cardiovasc Surg 1982;84:489-96.

14. Mitchell JD, Mathisen DJ, Wright CD, et al. Clinical experience with carinal resection. J Thorac Cardiovasc Surg 1999;117:39-52; discussion 52-3.

15. Tsuchiya R, Goya T, Naruke T, et al. Resection of tracheal carina for lung cancer. Procedure, complications, and mortality. J Thorac Cardiovasc Surg 1990;99:779-87.

16. Porhanov VA, Poliakov IS, Selvaschuk AP, et al. Indications and results of sleeve carinal resection. Eur J Cardiothorac Surg 2002;22:685-94.

17. de Perrot M, Fadel E, Mercier O, et al. Long-term results after carinal resection for carcinoma: does the benefit warrant the risk? J Thorac Cardiovasc Surg 2006;131:81-9.

18. Eichhorn F, Storz K, Hoffmann H, et al. Sleeve pneumonectomy for central non-small cell lung cancer: indications, complications, and survival. Ann Thorac Surg 2013;96:253-8.

19. Li J, Wang W, Jiang L, et al. Video-Assisted Thoracic Surgery Resection and Reconstruction of Carina and Trachea for Malignant or Benign Disease in 12 Patients: Three Centers' Experience in China. Ann Thorac Surg 2016;102:295-303.

20. Zhao G, Dong C, Yang M, et al. Totally thoracoscopic tracheoplasty for a squamous cell carcinoma of the mediastinal trachea. Ann Thorac Surg 2014;98:1109-11.

21. Jiao W, Zhu D, Cheng Z, et al. Thoracoscopic tracheal resection and reconstruction for adenoid cystic carcinoma. Ann Thorac Surg 2015;99:e15-7.

22. Peng Q, Zhang L, Ren Y, et al. Reconstruction of Long Noncircumferential Tracheal or Carinal Resections With Bronchial Flaps. Ann Thorac Surg 2019;108:417-23.

23. Shao WL, Liu LX, He JX, et al. Bronchial sleeve resection and reconstruction of pulmonary artery by videoassisted thoracic small incision surgery for central lung cancer: a report of 139 cases. Zhonghua Wai Ke Za Zhi 2007;45:1530-2.

24. Lanuti M, Mathisen DJ. Carinal resection. Thorac Surg Clin 2004;14:199-209.

25. Jiang F, Xu L, Yuan F, et al. Carinal resection and reconstruction in surgical treatment of bronchogenic carcinoma with carinal involvement. J Thorac Oncol 2009;4:1375-9.

26. Petersen RH, Hansen HJ. Learning thoracoscopic lobectomy. Eur J Cardiothorac Surg 2010;37:516-20.

27. Ujiie H, Yasufuku K. New era of "resection of the carina and lower trachea". J Thorac Dis 2017;9:4932-6. 
28. Vannucci F, Gonzalez-Rivas D. Is VATS lobectomy standard of care for operable non-small cell lung cancer? Lung Cancer 2016;100:114-9.

29. Cerfolio R, Louie BE, Farivar AS, et al. Consensus statement on definitions and nomenclature for robotic thoracic surgery. J Thorac Cardiovasc Surg 2017;154:1065-9.

30. Abbas AE. Surgical Management of Lung Cancer: History, Evolution, and Modern Advances. Curr Oncol Rep 2018;20:98.

Cite this article as: Girotti PNC. Editorial on: are we achieving ultimative limits of the minimally invasive thoracic surgery? Transl Lung Cancer Res 2021;10(11):4317-4321. doi: $10.21037 /$ tlcr-21-748
31. Li S, Ai Q, Liang H, et al. Non-intubated Robotic-Assisted Thoracic Surgery for Tracheal/Airway Resection and Reconstruction: Technique Description and Preliminary Results. Ann Surg 2021. [Epub ahead of print]. doi: 10.1097/SLA.0000000000004887.

32. Hu D, Wang Z, Tantai J, et al. Robotic-assisted thoracoscopic resection and reconstruction of the carina. Interact Cardiovasc Thorac Surg 2020;31:912-4. 